ARTICLE

Received 10 Feb 2015 | Accepted 13 Jul 2015 | Published 24 Aug 2015

DOI: $10.1038 /$ ncomms 9054

OPEN

\title{
Tbx15 controls skeletal muscle fibre-type determination and muscle metabolism
}

\author{
Kevin Y. Lee ${ }^{1}$, Manvendra K. Singh ${ }^{2,3}$, Siegfried Ussar ${ }^{1,4}$, Petra Wetzel ${ }^{5}$, Michael F. Hirshman',
} Laurie J. Goodyear ${ }^{1}$, Andreas Kispert ${ }^{2} \&$ C. Ronald Kahn ${ }^{1}$

Skeletal muscle is composed of both slow-twitch oxidative myofibers and fast-twitch glycolytic myofibers that differentially impact muscle metabolism, function and eventually whole-body physiology. Here we show that the mesodermal transcription factor T-box 15 (Tbx15) is highly and specifically expressed in glycolytic myofibers. Ablation of Tbx15 in vivo leads to a decrease in muscle size due to a decrease in the number of glycolytic fibres, associated with a small increase in the number of oxidative fibres. This shift in fibre composition results in muscles with slower myofiber contraction and relaxation, and also decreases whole-body oxygen consumption, reduces spontaneous activity, increases adiposity and glucose intolerance. Mechanistically, ablation of Tbx15 leads to activation of AMPK signalling and a decrease in Igf2 expression. Thus, Tbx15 is one of a limited number of transcription factors to be identified with a critical role in regulating glycolytic fibre identity and muscle metabolism.

\footnotetext{
${ }^{1}$ Section on Integrative Physiology and Metabolism, Joslin Diabetes Center, Harvard Medical School, 1 Joslin Plaza, Boston, Massachusetts 02215, USA.

2 Institut für Molekularbiologie, Medizinische Hochschule Hannover, Carl-Neuberg-Str. 1, D-30625 Hannover, Germany. ${ }^{3}$ Signature Research Program in Cardiovascular and Metabolic Disorders, Duke-NUS Graduate Medical School Singapore, National Heart Centre Singapore, 8 College Road, Singapore 169857, Singapore. ${ }^{4}$ Institute for Diabetes and Obesity, Helmholtz Center, Parkring, 1385748 Munich/Garching, Germany. ${ }^{5}$ Zentrum Physiologie, Medizinische Hochschule Hannover, Carl-Neuberg-Str. 1, D-30625 Hannover, Germany. Correspondence and requests for materials should be addressed to C.R.K. (email: C.Ronald.Kahn@joslin.harvard.edu).
} 
T he association of type 2 diabetes mellitus with obesity and inactivity illustrates the important link between energy homeostasis and the development of metabolic disease. Skeletal muscle, because of its high oxidative capacity and large contribution to total body mass, is an important tissue in maintaining normal whole-body metabolism and energy homeostasis.

In mammals, skeletal muscles are composed of a mosaic of different fibre types. Slow-twitch (type I) myofibers are rich in the mitochondria, have high oxidative capacity and high capillary density, whereas fast-twitch (type II) fibres have lower mitochondrial and capillary density and generate ATP primarily through glycolysis. A number of studies have demonstrated that individuals with type 2 diabetes mellitus or obesity have more glycolytic fibres and less oxidative fibres than healthy individuals ${ }^{1-4}$. Indeed, fibre-type distribution has been shown to directly correlate with glucose uptake and insulin resistance in humans ${ }^{5}$.

The molecular regulation of fibre-type determination is not completely understood. However, recent studies have begun to identify some of the pathways that interact to affect fibre-type distribution. For example, pathways that drive the formation of oxidative myofibers include those mediated by AMP-activated protein kinase (AMPK), peroxisome proliferator-activated receptor gamma co-activator 1-alpha (PGC-1 $\alpha$ ), calcineurin and protein kinase $\mathrm{C}^{6-10}$. On the other hand, glycolytic muscle determination is, at least in part, controlled by the transcriptional co-activator Baf60c and involves activation of Akt through the mTor-interacting protein Deptor ${ }^{11}$.

Tbx 15 is a member of the T-box gene family that contains 17 different members in mammals. The first T-box gene characterized was Brachyury (T), a gene known to play a major role in mesodermal development in all vertebrates ${ }^{12}$. The T-box transcription factors share a characteristic sequence similarity within the DNA-binding domain (T-domain) that is involved in control of a variety of developmental processes ${ }^{13}$, including mesoderm specification, somite segmentation and left/right body axis determination ${ }^{14}$. Complete inactivation of the $T b x 15$ gene in mice and mutations of TBX15 in humans result in severe skeletal malformation ${ }^{15-17}$. Depending on cellular context, Tbx15 can activate gene transcription, or through its interactions with co-repressors of the Groucho family, repress gene transcription ${ }^{18}$.

Work from our lab has demonstrated that Tbx15 is differentially expressed between different adipose tissue depots, and its expression in human visceral adipose depots is strongly downregulated in overweight and obese individuals ${ }^{19}$. In addition, genome-wide association studies have shown that single-nucleotide polymorphisms within the TBX15 gene correlate independently with both body mass index and waist-hip ratio, a measure of central obesity ${ }^{20}$. In vitro, we have shown that Tbx15 negatively regulates mitochondrial mass and activity in pre-adipocytes, suggesting a role in the control of oxidative versus glycolytic metabolism ${ }^{21}$. Consistent with this, Tbx15 was recently also identified in a panel of genes that were more highly expressed in glycolytic than oxidative muscle ${ }^{11}$.

The ability of Tbx15 to regulate mitochondrial mass and activity, its high expression in glycolytic muscle, and the correlation of both polymorphisms and expression of Tbx15 to obesity lead us to hypothesize that Tbx15 might regulate metabolic function and fibre type in skeletal muscle. In the current study, we show that Tbx15 is specifically expressed in glycolytic muscle fibres. Ablation of Tbx15 leads to a decrease in glycolytic fibres and increase in oxidative fibres. This leads to the generation of skeletal muscle with increased oxidative fibre density and slow contractile properties. Loss of Tbx15 also causes a dose-dependent increase in fibre size. Heterozygous deletion in mice $\left(T b \times 15^{+/-}\right)$results in a milder shift in fibre type, increased adiposity and glucose intolerance. In vitro studies indicate that Tbx15 acts through downregulation of the AMPK signalling pathway and $\operatorname{Ig} 2$, and exogenous administration of AMPK inhibitors or recombinant insulin growth factor 2 (Igf2) partially rescues the metabolic phenotypes and abnormal morphology of Tbx15 knockdown myotubes. Taken together, these data indicate that Tbx15 has a critical role in regulating muscle fibre type, muscle metabolism and whole-body physiology.

\section{Results}

Tbx15 is highly and specifically expressed in glycolytic myofibers. Tbx15 is a mesodermal gene involved in normal skeletal and muscle development ${ }^{17}$. In Tbx $15^{\text {LacZ/+ }}$ mice, in which the LacZ gene replaced exon 3 of the Tbx15 gene creating a fusion protein allowing tracking of $T b \times 15$ expression $^{17}$, there was robust X-gal staining in the skeletal muscle with no staining in the control (Fig. 1a). In $\mathrm{C} 2 \mathrm{C} 12$ myoblasts, expression of $\mathrm{Tb} \times 15$ messenger RNA (mRNA) increased $\sim 12$-fold during differentiation, and this was confirmed by western blot analysis (Fig. 1b). Northern blot and quantitative PCR ( $\mathrm{PPCR}$ ) analysis of mouse tissues revealed that Tbx15 expression was at least eight times higher in muscle than adipose tissue, skin and pancreas, with much lower levels in other tissues (Fig. 1c; Supplementary Fig. 1a).

Assessment of individual muscles showed that Tbx15 mRNA was over two-fold higher in glycolytic muscles, such as the extensor digitorum longus (EDL), gastrocnemius and tibialis anterior, than in the oxidative muscle, such as soleus; and this was confirmed by western blot analysis (Fig. 1d). Fluorescent in situ hybridization on quadriceps muscle of wild-type mice demonstrated that Tbx15 message was not uniformly expressed, but in a mosaic pattern of fibre types. Similarly, immunofluorescence for Tbx15 in tibialis anterior muscle, which contains a mixture of oxidative and glycolytic fibres, confirmed that Tbx 15 was expressed in a fibre-type-specific manner (Fig. 1e).

To determine which specific fibres exhibited high Tbx15 expression, we stained individual muscles from $T b x 15^{L a c Z}$ mice. As shown in Fig. 1f, Tbx15-related X-gal staining was observed only in the glycolytic EDL muscle and not in the oxidative soleus muscle. When sections from tibialis anterior muscle were double stained using antibodies to Tbx15 and myosin IIa, it was clear that Tbx15 was virtually absent from type IIa, fast-twitch, oxidative fibres (Supplementary Fig. 1c). Furthermore, when serial sections were stained for succinate dehydrogenase (SDH), a marker of mitochondrial activity, $<20 \%$ of the oxidative fibres, but over $80 \%$ of the glycolytic muscle fibres, scored positive for Tbx15 expression (Fig. 1g,h). Taken together, these data indicate that Tbx15 is expressed almost exclusively fast-twitch, glycolytic muscle. Interestingly, immunofluorescence also showed that Tbx15 was expressed in both the cytoplasm and nuclei of muscle fibres. These findings were confirmed by cell fractionation studies of skeletal muscle, which showed Tbx15 was present in the cytoplasm, microsomal fraction, and the nucleus (Supplementary Fig. 1b). Antibody specificity was verified by the absence of positive signal in both western blot analysis and immunofluorescence of Tbx15 in $\mathrm{Tb} \times 15^{-/-}$muscle (Fig. 2a; Supplementary Fig. 1d).

Endurance exercise in both humans and mice has been shown to lead to an increase in oxidative and decrease in glycolytic fibre density $^{22}$. qPCR analysis revealed that 3 weeks of voluntary wheel cage running reduced mRNA Tbx 15 levels by $15 \%$ in 6-week-old wild-type (WT) males. This is consistent with a reduction in glycolytic fibres, as myosin IIb mRNA levels were reduced $19 \%$. Other markers of oxidative metabolism, including Pgc- $1 \alpha$, SDH, 
a

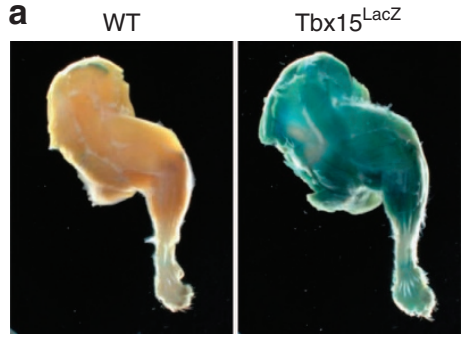

b
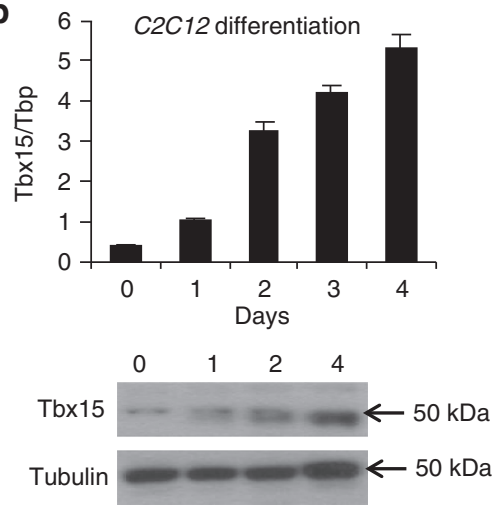

C
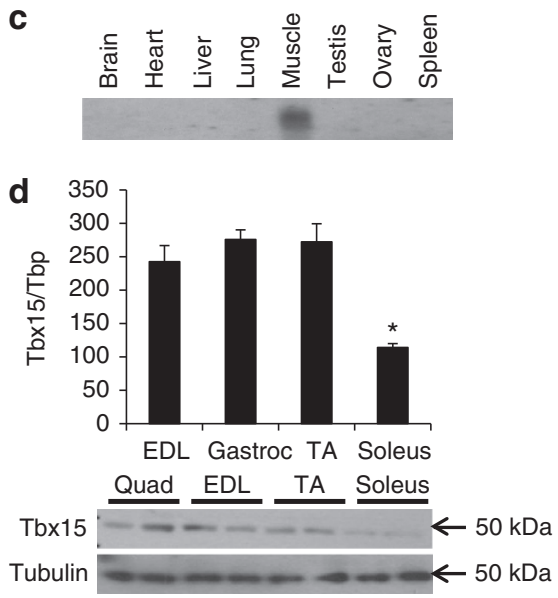

e In situ hybridization

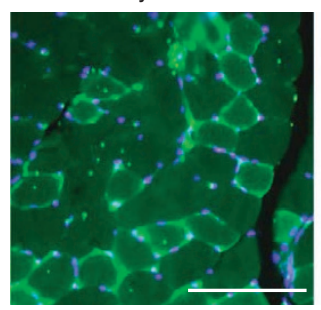

f
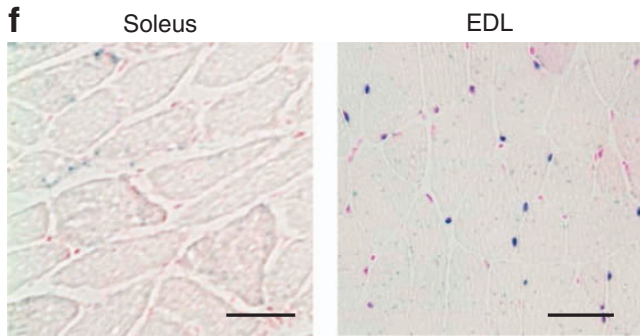

g
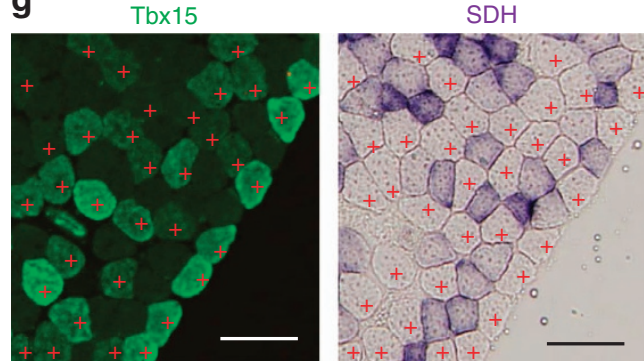

h

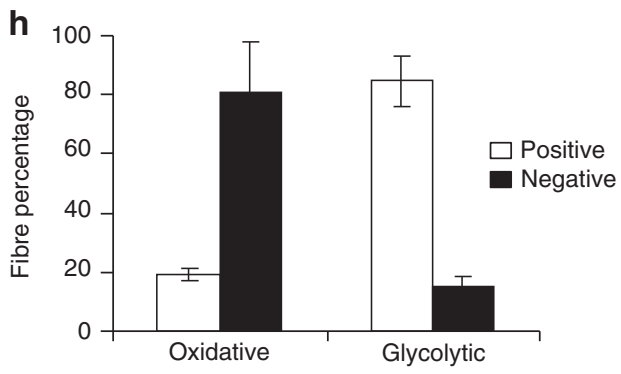

Figure 1 | Tbx15 is highly and specifically expressed in glycolytic skeletal muscle. (a) X-gal-stained hind limbs from 3-month-old Tbx15 ${ }^{\text {LacZ } /+}$ males. (b) qPCR analysis of Tbx15 expression from $\mathrm{C} 2 \mathrm{C} 12$ cells during myogenic differentiation. Data are shown as mean \pm s.e.m. of triplicate samples and repeated three times (upper panel). Western blot of Tbx15 from protein extracts from the same cells using tubulin as a loading control (lower panel). (c) Expression level of Tbx15 mRNA was compared by northern blot of RNA isolated from tissues from of 8-week-old male and female (ovary) C57BL/6 mice. This experiment has been performed once. (d) qPCR analysis of Tbx15 expression from muscle groups of 8-week-old male C57BL/6 mice. Data are shown as mean \pm s.e.m. of six samples (upper panel). Western blot of Tbx15 from protein extracts made from the same muscles using tubulin as a loading control (lower panel). (e) Fluorescent in situ hybridization for Tbx15 in quadriceps muscle and immunofluorescence for Tbx15 in tibialis anterior muscle of 8-weekold random fed male mice. The photographs were taken at $\times 10$ magnification. The photographs were taken at $\times 10$ magnification. Scale bar, $100 \mu \mathrm{M}$. (f) $X$-gal-stained representative sections of soleus and EDL from 8-week-old Tbx15 LacZ males $(n=3)$. Slides were lightly counterstained with eosin. Pictures were taken at $\times 20$ magnification. Scale bar, $50 \mu \mathrm{M}$. (g) Immunofluorescence for Tbx15 and succinate dehydrogenase staining was performed on serial sections of tibialis anterior muscle of 8-week-old random fed male mice. Glycolytic fibres are marked with red crosses. The photographs were taken at $\times 10$ magnification. Scale bar, $100 \mu \mathrm{M}$ (h) Immunofluorescence for Tbx15 and succinate dehydrogenase staining was performed on serial sections. Five digital images $(\times 20)$ from non-overlapping fields were taken from each slide (total 20 fields per group), and oxidative and glycolytic muscle fibres were scored for Tbx15 expression. Values are mean \pm s.e.m. of four animals.

as well as markers of oxidative fibres, myosin I and myosin IIa, were all increased in exercised muscle (Supplementary Fig. 1e).

Ablation of Tbx15 leads to a decrease in glycolytic myofibers. To define the role of Tbx15 in skeletal muscle, we studied homozygous (Tbx $15^{-/-}$) and heterozygous Tbx15 knockout $\left(T b \times 15^{+/-}\right)$mice. As previously reported, homozygous Tbx15 knockout animals had shortened limbs and other skeletal malformations ${ }^{17}$, whereas overt developmental abnormalities were noted in the heterozygous knockout animals. qPCR and western blot analysis of quadriceps muscle at 6 weeks of age shows that Tbx15 expression was reduced by about $\sim 40 \%$ in the heterozygous knockout animals and completely abrogated in the homozygous knockout (Fig. 2a). Despite the lack of gross abnormalities, heterozygous ablation of Tbx15 led to a significant 
a
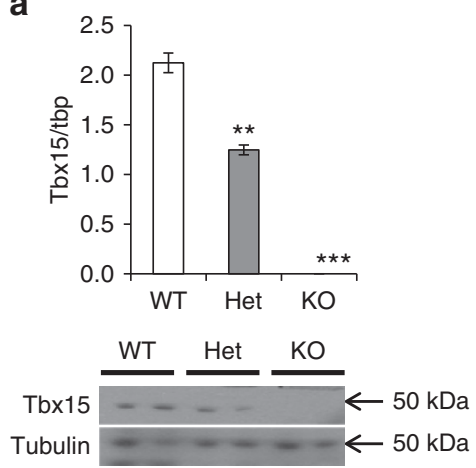

b

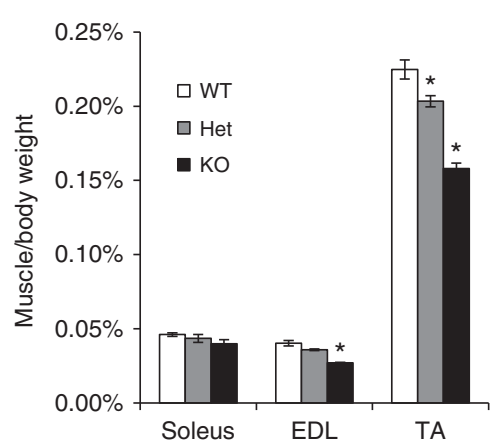

C

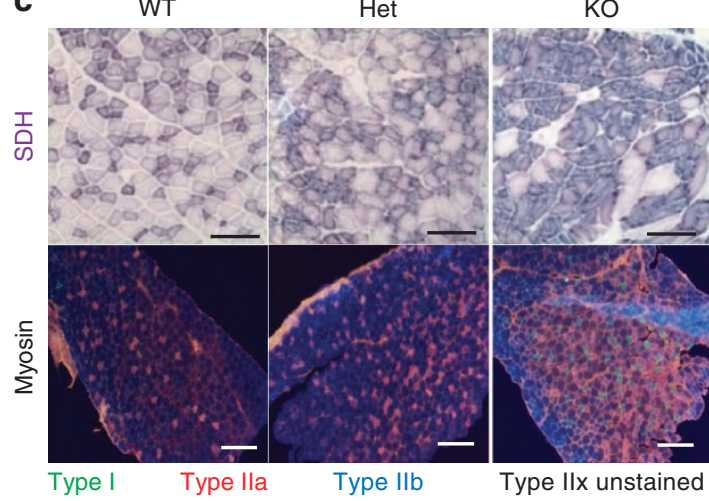

e

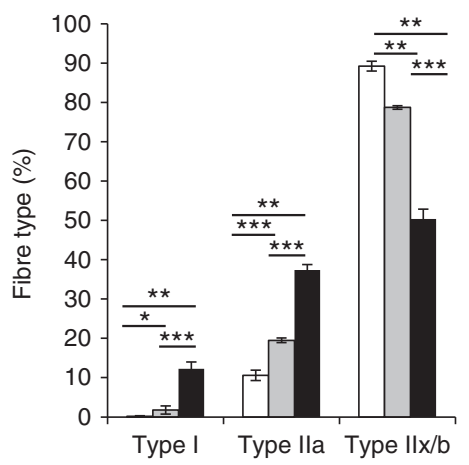

d

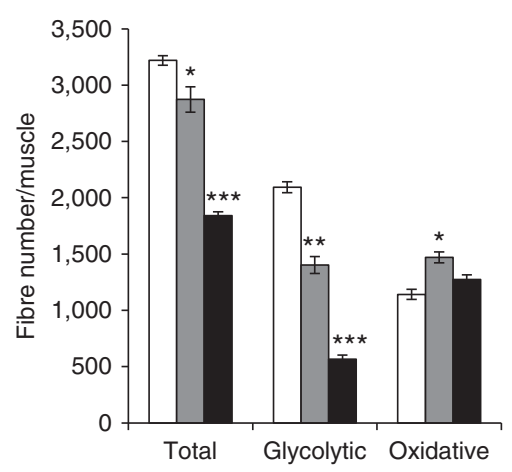

f Single twitch
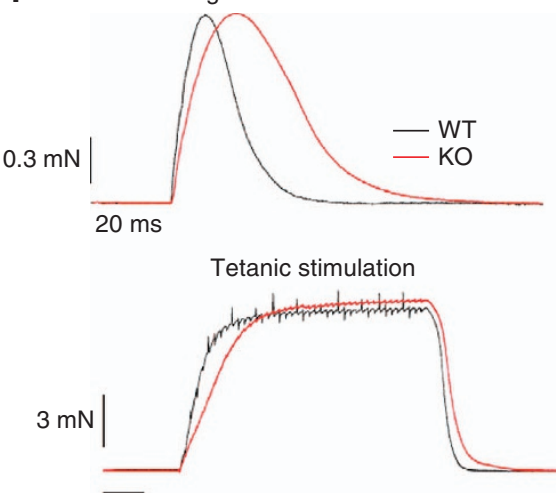

$\overline{80 \mathrm{~ms}}$

Figure 2 | Ablation of Tbx15 increases oxidative fibre density, reduces muscle mass and increases fibre diameter. (a) qPCR analysis for Tbx15 mRNA of RNA isolated from the tibialis anterior of male wild-type (WT), Tbx15 ${ }^{+/-}$and $T b \times 15^{-/-}$mice at 6-8 weeks of age. Data are shown as mean \pm s.e.m. of three to eight animals per group. Asterisks indicate significant differences in all panels. $\left({ }^{\star} P<0.05 ;{ }^{\star \star} P<0.01 ;{ }^{\star \star \star} P<0.001\right.$ by analysis of variance). (b) Mass of soleus, extensor digitorum longus (EDL) and tibialis anterior (TA) of male WT, $T b x 15^{+/-}$and Tbx15 ${ }^{-/-}$mice at 6-8 weeks of age normalized to body weight. Data are shown as mean \pm s.e.m. of three to eight animals per group. (c) Succinate dehydrogenase (SDH) staining (top panels) from tibealis anterior and immunofluorescence for myosin I, Ila and Ilb (bottom panels) from WT, Tbx15 $+/-$ and Tbx $15^{-/-}$EDL muscle. SDH pictures are taken at $\times 20$. Scale bar, $100 \mu \mathrm{M}$. Myosin immunofluorescence pictures are taken at $\times 10$. Scale bar, $200 \mu \mathrm{M}$. (d) Quantitation of glycolytic and oxidative muscle fibres from the rectus femoris quadriceps muscle of male WT, Tbx15 $/ /-$ and $T b \times 15^{-/-}$mice at 6-8 weeks of age. Data are shown as mean \pm s.e.m. of three to eight animals per group. (e) Quantitation of fibre types from the EDL muscle of male WT, Tbx15 ${ }^{+/-}$and Tbx $15^{-/-}$mice at 6-8 weeks of age. Data are shown as mean \pm s.e.m. of three to four muscles per group. (f) Representative recordings of single-twitch contraction and tetanic stimulation of EDL fibre bundles from WT and Tbx15-/- mice at 3-4 months of age $(n=8-10)$.

$\sim 10 \%$ reduction in muscle mass (even when normalized to body weight) of both the EDL and tibialis anterior muscles, which are comprised mainly of glycolytic fibres. By contrast, there was no change in the weight of the more oxidative soleus muscle. The reduction in muscle mass was even more marked in $T b \times 15^{-/-}$ mice with a $20-25 \%$ reduction in weight of the EDL and tibialis anterior muscles, again with no changes in the soleus muscle weight (Fig. 2b).

On histological examination of tibialis anterior from 6-weekold animals, there was a moderate increase in the relative density of oxidative, SDH positive fibres in the heterozygous knockout mice and a marked increase in the homozygous knockout compared with controls, in both cases with a corresponding decrease in glycolytic, SDH negative fibres (Fig. 2c). Quantitation of fibres from SDH-stained quadriceps muscle revealed a reduction in the total number of fibres of $11 \%$ in heterozygous and $43 \%$ in homozygous knockout mice. This reduction was due to a specific and gene dose-dependent reduction in the number of glycolytic muscle fibres of $33 \%$ in heterozygous and $72 \%$ in homozygous knockout mice (Fig. 2d). On the other hand, the number of oxidative fibres was significantly increased by $28 \%$ in heterozygous and was also increased by $12 \%$ in the muscle of homozygous knockout mice, although the latter did not quite reach statistical significance (analysis of variance; $P=0.1$ ).

Muscle fibre-type assessment by immunofluorescent staining for myosin heavy chain isoforms revealed that ablation of Tbx15 led to the appearance of considerable numbers of type I fibres in Tbx $15^{+/-}$and $T b \times 15^{-/-}$EDL compared with WT mice, which have virtually no type I fibres in EDL muscle (Fig. 2c). Furthermore, these EDL muscles had a 2-3.5-fold increase in type IIa fibre density compared with controls. This increase in oxidative fibre density is due to a transformation of fibres into oxidative type I and type IIa fibres, as well as a reduction in glycolytic IIb fibres by 12 and $44 \%$ in the $T b \times 15^{+/-}$and Tbx $15^{-/-}$EDL, respectively (Fig. 2e). Interestingly, despite the reduction in muscle weight being caused by a reduction in the number of glycolytic fibres in $T b \times 15^{+/-}$and $T b \times 15^{-/-}$mice, the cross-sectional area (CSA) of the remaining glycolytic fibres was significantly increased by 13 and $46 \%$ in tibialis anterior muscles of $T b \times 15^{+/-}$and $T b \times 15^{-/-}$animals, respectively. CSA of oxidative fibres was also increased by 18 and $57 \%$ in tibialis anterior muscles of $T b \times 15^{+/-}$and $T b \times 15^{-/-}$animals, respectively (Supplementary Fig. 2a). These changes in fibre size were associated with a change and broadening of distribution, as 
reflected in the s.d. of fibre size within each animal. This is true for both the glycolytic and oxidative fibres of $T b \times 15^{+/-}$and $\mathrm{Tb} 15^{-/-}$muscles, respectively (Supplementary Fig. $2 \mathrm{~b}-\mathrm{c}$ ).

Ablation of Tbx15 leads to a decreased rate of muscle contraction. Since muscle fibre-type controls contraction and relaxation rates of skeletal muscle, with oxidative fibres characterized as slow-twitch and glycolytic fibres as fast twitch, we analysed the impact of loss of Tbx15 on muscle contractile properties. Both twitch and tetanic contraction were tested ex vivo using small fibre bundles of the EDL, normally a fast-twitch muscle. Recordings of single twitches were analysed for peak force, time to peak (TTP), and 50 and $75 \%$ relaxation times ( $\mathrm{t} 50$ and $\mathrm{t} 75 \%$; Fig. 2f; Supplementary Fig. 2d). During single-twitch contraction, peak force was not altered, however. the rate of contraction, as measured by time to peak, was prolonged by $\sim 30 \%$ in Tbx15 $1-$ muscles characteristic of slow, oxidative fibres. Likewise, muscle relaxation, as indicated by increased t50 and t $75 \%$ values, was retarded in $T b \times 15^{-1-}$ mice by $\sim 35 \%$. After tetanic stimulation, muscle fibres of $T b \times 15^{-/-}$mice also demonstrated a $\sim 30 \%$ slower relaxation rate, as indicated by increase $\mathrm{t} 50$ and $\mathrm{t} 75 \%$ values, compared with WT, again with no change in peak force (Supplementary Fig. 2d).

Ablation of Tbx15 does not affect skeletal muscle performance. To test whether the ablation of Tbx15 led to changes in muscle performance, we performed several tests of muscle performance both ex vivo and in vivo. In agreement with the results found in Tbx15 $15^{-/}$mice, no differences in maximal twitch force or tetanic force were observed in EDL muscle from $\mathrm{Tb} \times 15^{+/-}$mice compared with WT controls (Supplementary Fig. 2e-f). There was also no difference in fatigue resistance, as assessed by reduction in maximal tetanic force after repeatedly stimulated (Supplementary Fig. 2g).

In a treadmill exercise paradigm on 8-week-old male mice, there was no significant difference in the running time $\left(13.6 \pm 1.5 \mathrm{~min}\right.$ for WT versus $13 \pm 1.1 \mathrm{~min}$ for $\mathrm{Tbx} 15^{+/-}$, $n=6-8)$ or the total distance run $(126.5 \pm 21.5 \mathrm{~m}$ versus $122.5 \pm 10.7 \mathrm{~m}$; Supplementary Fig. 2h). Likewise, no differences were observed in grip strength $(67.3 \pm 3.0$ versus $62.8 \pm 3.1 \mathrm{~g}$, $n=12-14$; Supplementary Fig. 2i). Finally, although two separate cohorts of Tbx15 $5^{+/-}$males tended to show less voluntary wheel running than control mice $(8.06 \pm 0.70 \mathrm{~km}$ per day for WT versus $7.16 \pm 0.61 \mathrm{~km}$ per day for Tbx15 $1 /-, n=6)$, this was not statistically significant (Supplementary Fig. $2 \mathrm{j}$ ). Thus, even though Tbx15 ablation caused both cellular and molecular changes in skeletal muscle, standard tests of muscle performance were not significantly affected.

Tbx15 ablation causes glucose intolerance and obesity. Factors that affect muscle fibre-type distribution and size can lead to alterations in whole-body physiology and metabolism ${ }^{22,23}$. Since homozygous Tbx15 knockout animals exhibited obvious developmental abnormalities that might also affect metabolic physiology, we focused our assessment on developmentally normal, heterozygous Tbx15 knockout animals. At 5 months of age, $T b \times 15^{+/}-$mice fed a standard chow ( $21 \%$ fat by calories) exhibited no differences from WT in body weight, fed or fasting blood glucose, and circulating insulin levels (Fig. 3a; Supplementary Fig. 3a-b). However, when challenged with an intraperitoneal glucose tolerance test, 5 -month-old $\mathrm{Tb} \times 15^{+/-}$mice showed impaired glucose tolerance with a $43 \%$ increase in peak glucose levels (Fig. 3b). This occurred with no change in insulin tolerance, or insulin levels during the intraperitoneal glucose tolerance test (Supplementary Fig. 3c-d). At this age, Dual-energy
X-ray absorptiometry (DEXA) analysis revealed that $T b \times 15^{+/-}$ mice had no change in lean mass, but a $21 \%$ increase in fat tissue mass compared with controls (Fig. 3c). Haematoxylin/eosin staining, Oil Red $\mathrm{O}$ staining and biochemical analysis of the livers from 6-month-old $\mathrm{Tb}_{1015^{+/-}}$animals also revealed a threefold increase in hepatic lipid accumulation, with no increase in muscle triglyceride content (Fig. 3d,e).

Indirect calorimetry of 5-month-old mice revealed that Tbx $15^{+/-}$males had $\sim 12 \%$ decrease in average oxygen consumption during both the light phase $(3,386+174$ versus $3,038+75 \mathrm{ml} \mathrm{kg}^{-1}$ lean mass per hour in control versus Tbx15 $1 /$ mice $)$ and dark phase $(3,049+120$ versus $2,688 \pm 53 \mathrm{ml} \mathrm{kg}^{-1}$ lean mass per hour) of the diurnal cycle (Supplementary Fig. 3d) with no change in respiratory quotient (Supplementary Fig. 3e). Although the differences in oxygen consumption did not quite reach statistical significance (Student's $t$-test; $P=0.1$ ), similar trends were observed in three separate cohorts of mice. This tendency of decreased oxygen consumption was associated with a significant $25-30 \%$ decrease in spontaneous activity of $T b \times 15^{+/-}$mice during both the light phase $(93 \pm 8$ versus $64 \pm 5$ counts per hour in control versus Tbx $15^{+/-}$mice per hour) and dark phase $(217 \pm 21$ versus $166 \pm 29$ counts per hour) of the diurnal cycle (Fig. 3f). Since Tbx15 is almost exclusively expressed in skeletal muscle, with no detectable expression in the brain during any period in development, the reduction in activity after Tbx15 ablation is presumably due to its effects on the skeletal muscle. Thus, although heterozygous deletion of Tbx15 does not impair exercise-induced activity, it does result in decreased spontaneous activity that, at least in part, contributes to an increase in adiposity and hepatosteatosis.

Tbx15 regulates oxidative capacity and AMPK signalling. To further investigate the mechanisms underlying the loss of glycolytic fibres and increase in oxidative fibres observed in the mice with reduced $T b \times 15$, we created $\mathrm{C} 2 \mathrm{C} 12$ myoblast cell lines with a stable knockdown of Tbx15 expression (shTbx15 cells) and compared them with $\mathrm{C} 2 \mathrm{C} 12$ cells with stable overexpression of Tbx15 (pBABE-Tbx15). qPCR and western blot analysis demonstrated that Tbx15 mRNA and Tbx15 protein were reduced $>90 \%$ in shTbx15 cells and increased $\sim 20$-fold in pBABE-Tbx15 cells (Fig. 4a).

AMPK signalling has been shown to be both necessary and sufficient to transform glycolytic muscle fibres into oxidative fibres ${ }^{8,10}$. Western blot analysis of control and shTbx15 myoblasts demonstrated a robust increase in phosphorylation of AMPK on Thr172 and its downstream substrate acetyl-CoA carboxylase (ACC) on Ser79 compared with controls (Fig. 4b), with no change in total levels of AMPK or ACC. This was confirmed in vivo in extracts of muscle from $\mathrm{Tb} \times 15^{+/}-$mice, which showed an increase in AMPK Thr172 and ACC Ser79 phosphorylation (Fig. 4c).

Activation of AMPK signalling usually leads to an enhancement of oxidative metabolism and increased oxygen consumption rates (OCRs $)^{24}$. Indeed, although whole-body oxygen consumption tended to be decreased in $\mathrm{Tb} \times 15^{+/-}$ mice, knockdown of $\mathrm{Tb} \times 15$ in $\mathrm{C} 2 \mathrm{C} 12$ cells resulted in a $33 \pm 6 \%$ increase in basal OCRs, and treatment of the shTbx 15 and control myotubes with the AMPK inhibitor, compound C, reduces OCR in both the groups (Fig. 4d; Supplementary Fig. 4a). Conversely, overexpression of Tbx 15 in $\mathrm{C} 2 \mathrm{C} 12$ myoblasts resulted in a decrease in basal OCR by $34 \pm 1 \%$ compared with controls (Fig. 4d). Thus, reduction of Tbx15 both in vivo and in vitro leads to an activation of the AMPK signalling pathway. At the cellular level, this leads to an increase in 
a

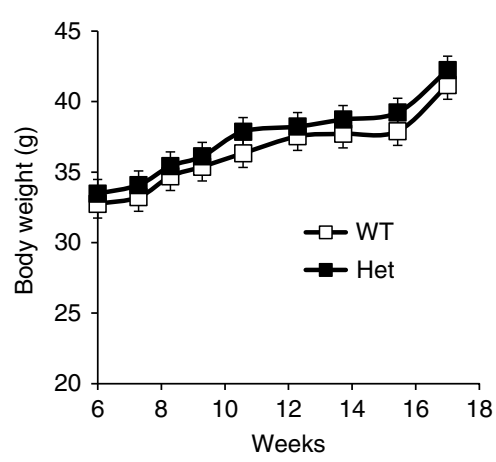

b

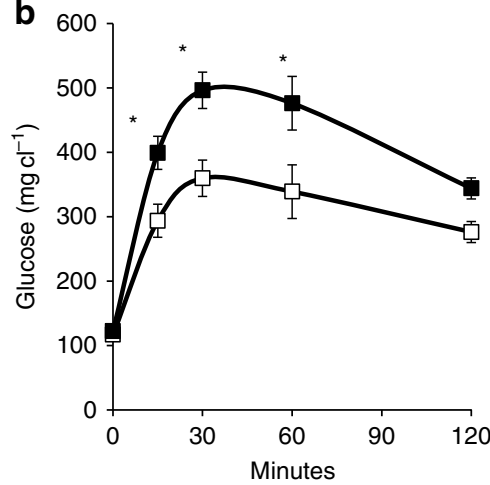

c

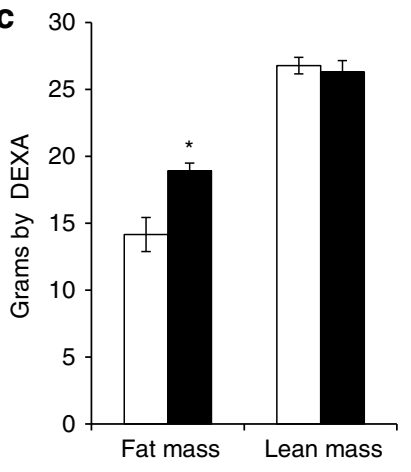

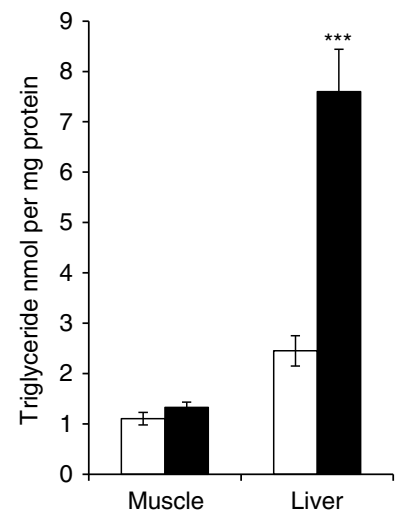

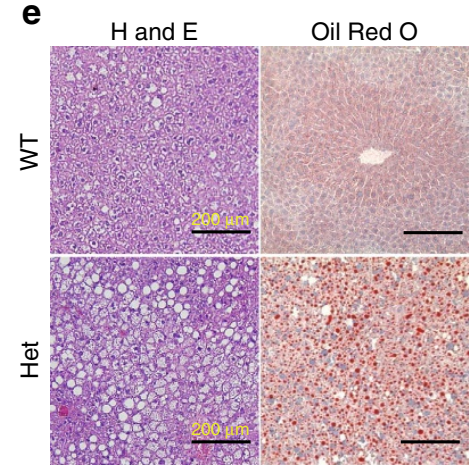

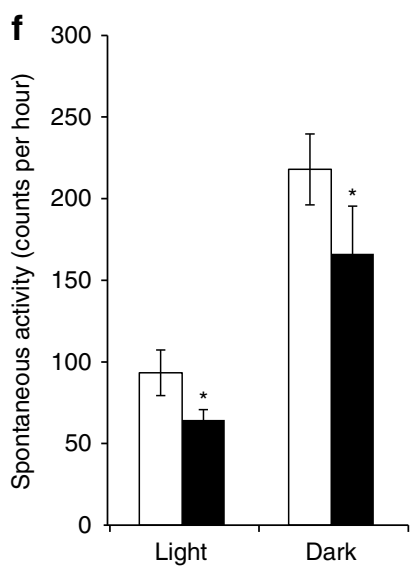

Figure 3 | Tbx15 ${ }^{+/-}$males are resistant to high-fat diet-induced obesity. (a) Body weights of $T b \times 15^{+/-}$and control males during 10 weeks on high-fat diet or chow diet (started at 6 weeks of age). Data are shown as mean \pm s.e.m. of 10-12 animals per group. (b) Glucose tolerance testing of 5-month-old $\mathrm{Tb} \times 15^{+/}-$and control males. Data are shown as mean \pm s.e.m. of $10-12$ animals per group $\left({ }^{\star} P<0.05\right.$ for all panels by Student's $t$-test or Mann-Whitney $U$ statistical tests). (c) Lean and fat mass from 6-month-old $T b \times 15^{+/-}$and control males. Data are shown as mean \pm s.e.m. of six to seven animals per group. (d) Triglyceride quantitation from liver and muscle extracts of 6-month-old Tbx15 $+/-$ and control males. Data are shown as mean \pm s.e.m. of six animals per group. (e) Haematoxylin and eosin staining (left panels) and Oil Red O staining (right panels) of 6-month-old Tbx $15^{+/-}$and control livers. Nuclei are counterstained with haematoxylin. Representative digital images $(\times 20)$ are shown. Scale bar, $200 \mu$ M. (f) Spontaneous activity the light and dark cycles of pads from 5-month-old $\mathrm{Tbx}_{15^{+/}}$- and control males. Data are shown as mean \pm s.e.m. of six animals per group.

oxidative metabolism in $\mathrm{C} 2 \mathrm{C} 12$ myoblasts, but this effect is masked in vivo, as a result of the decreased activity of the Tbx $15^{+/-}$mice.

AMPK has a well-established role in regulating insulin resistance, and activation of AMPK has been to shown to directly inhibit mTor signalling ${ }^{25,26}$. To examine the effects of AMPK activation we observed on ablation of Tbx15, we investigated insulin and mTOR signalling in fasted WT and Tbx15 $1-$ muscle $15 \mathrm{~min}$ after intravenous administration of insulin. Although insulin stimulation robustly increased phosphorylation of AKT S473 and ERK T202/Y204, no differences in total AKT or ERK proteins or in the phosphorylation of these proteins was observed between WT and Tbx $15^{+/-}$muscle (Fig. 4e). Likewise, qPCR analysis showed no changes in the glycolytic muscle-specific regulators of Akt activation, Baf60c and Deptor ${ }^{11}$ (Supplementary Fig. 4b-c) or other regulators of muscle fibre type, including PGC- $1 \alpha$, PGC- $1 \beta$, RIP140, calcineurin or Ppar-delta (Supplementary Fig. 5). However, after insulin stimulation, levels of phosphor mTor S2448 as well as its downstream phosphorylation target $\mathrm{p} 70^{\mathrm{S} 6 \mathrm{~K} 1}$ T389 were significantly reduced in Tbx15 $5^{+/}$muscle, with no changes in levels of total mTor or p70 ${ }^{\mathrm{S} 6 \mathrm{~K} 1}$ (Fig. $4 \mathrm{f}$ ). Since AMPK has been shown to repress activation of mTor signalling, these results are consistent with the marked activation of the AMPK signalling axis in Tbx15 $1 /-$ muscle.
Tbx15 regulates Igf2 levels both in vivo and in vitro. To determine possible transcriptional targets of Tbx15, we performed microarray analyses on shTbx15 and pBABE-Tbx15 myoblasts. Differentially regulated genes and pathways were analysed focusing on genes that were oppositely regulated in the Tbx15 knockdown and overexpressing cells. Genes that were significantly downregulated in $s h T b x 15$ and upregulated in pBABE-Tbx 15 (with fold change $\geq 1.5 ; \mathrm{q} \leq 0.10$ ) are found in Supplementary Table 3 , and genes that were significantly upregulated in shTbx15 and downregulated in pBABE-Tbx15 are shown in Supplementary Table 4. Gene set enrichment analysis and ingenuity pathway analysis of these data revealed that the Igf pathways were among the most significantly altered in the Tbx15 cellular models. In particular, the expression of the protein hormone Igf2 showed robust and opposite regulation in these Tbx15 cellular models.

qPCR analysis confirmed that the expression of Igf2 was increased over sevenfold in Tbx15 overexpressing cells and was decreased by over $70 \%$ in shTbx15 knockdown cells compared with controls (Fig. 5a). Since Igf2 is an important regulator of myogenesis and myoblast differentiation ${ }^{27}$, we investigated whether shTbx15 myoblasts that exhibit reduced Igf2 levels also had a defect in myogenesis. Indeed, compared with control myotubes, after 4 days of differentiation shTbx15 cells showed a reduced number of myotubes, but those that did form 
a
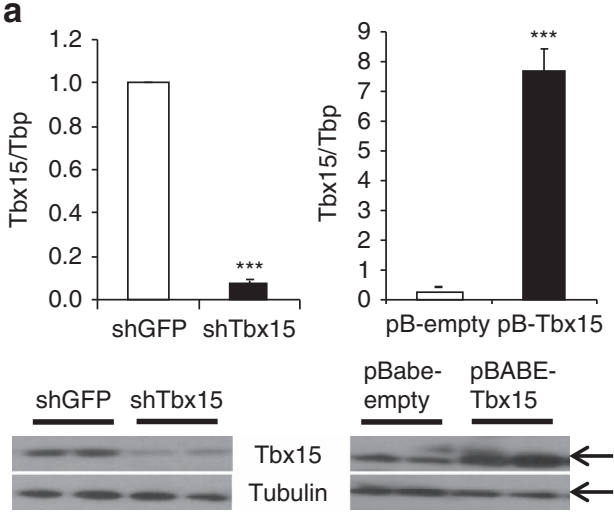

b
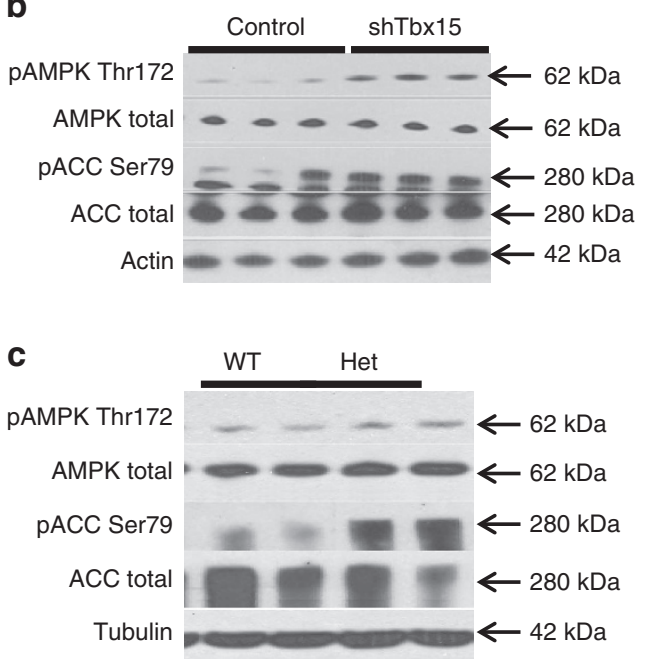

d

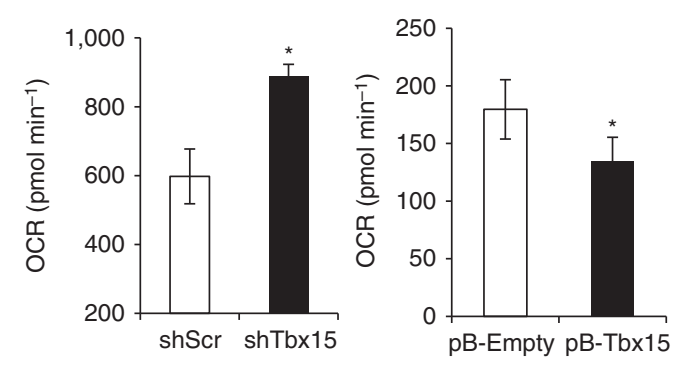

e
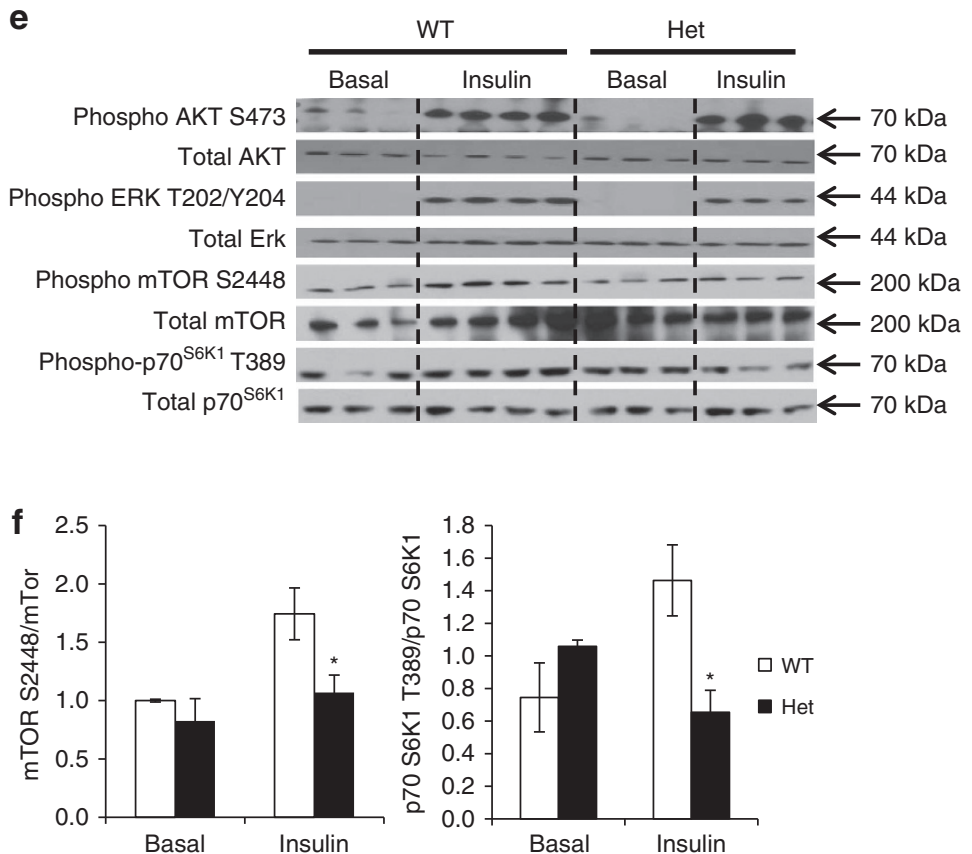

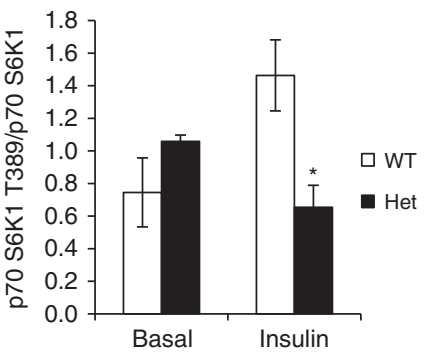

Figure 4 | Tbx15 regulates oxidative capacity and AMPK signalling in skeletal muscle. (a) Expression of Tbx15 mRNA and protein were compared by qPCR and western blot analysis between C2C12 myoblasts stably transfected with shTbx15 or shGFP (control), and C2C12 myoblasts stably transfected with pBABE-Tbx15 or pBABE-Empty (control). Data shown as mean \pm s.e.m. of three independently transfected samples and was repeated three times. Western blot of Tbx15 from protein extracts from the same cells. Western blot for tubulin was used as a loading control $\left({ }^{\star} P<0.05\right.$; ${ }^{\star \star} P<0.01$; ${ }^{\star \star \star} P<0.001$ for all panels by Student's t-test). (b) Western blot analysis of phosphorylation of AMP kinase (AMPK) at Thr172 and acetyl-CoA carboxylase (ACC) at Ser79 and total protein controls from myoblasts stably transfected with shTbx15 or controls. Actin is used as a loading control. (c) Western blot analysis of phosphorylation of AMPK at Thr172 and Acc1 at Ser79 and total protein controls from skeletal muscle of 6-week-old Tbx15 ${ }^{+/-}$and control males. Tubulin is used as a loading control. (d) Basal respiration of shTbx15, pBABE-Tbx15 and control C2C12 myoblasts was determined by calculating the area under the curve (AUC) during measurements of basal respiration. Values are means \pm s.e.m. of six to seven replicates. The whole experiment was repeated three times. (e) Western blot analysis of phosphorylation of AKT, ERK, mTOR, and p70 ${ }^{\mathrm{SK} 1}$ and total protein controls from tibealas anterior of in 10-week-old $\mathrm{Tb} \times 15^{+/-}$and control male mice $5 \mathrm{U}$ of insulin was injected per mouse and tissues were collected 15 min later. (f) Quantitation of western blots of phosphorylation of $\mathrm{mTOR}$, and $\mathrm{p} 7 \mathrm{O}^{\mathrm{SK} 1}$ and total protein controls in Supplementary Fig. 4a. Values are means \pm s.e.m. of six to seven replicates.

were both shorter and thicker than control differentiated cell (Fig. 5b, left panels). Although markers of myogenesis MyoD, Myf 4 and myogenin were normally induced in the knockdown cells, Igf2 levels remain reduced in the differentiated shTbx15 myotubes (Fig. 5c). In further support of a combined role for Tbx15 and Igf2 in myogenesis, in situ hybridization and immunofluorescence studies demonstrate that Tbx15 (Supplementary Fig. 6a) and Igf2 were highly and co-expressed in the developing, myosin-positive muscles of embryonic day 14.5 (E14.5) WT mice (Fig. 5d). In agreement with the cellular models, Tbx15 homozygous embryos demonstrated reduced Igf2 expression in developing muscles (Fig. 5d). This result was confirmed by qPCR of mRNA isolated from dissected limb muscle of E14.5 embryos, which showed $60-65 \%$ reductions of Igf 2 mRNA in both the Tbx $15^{+/-}$and $T b \times 15^{-/-}$animals. The levels of Igf2 and Tbx15 were $\sim 10$ - and $\sim 3$-fold higher, respectively, at E14.5 than at postnatal day 28 further suggesting a role for Tbx15 during development (Fig. 5e; Supplementary Fig. 6b).

Igf2 mediates Tbx15 action in skeletal muscle. Since Igf2 is regulated by Tbx15 levels and since Igf2 has been implicated to play a role in myogenesis and fibre-type specification ${ }^{28}$, we examined the muscles of $I g f 2$ knockout mice. As expected, muscle weights of $\operatorname{Igf} 2$ knockout mice were smaller $(\sim 60 \%)$ than littermate controls ${ }^{29}$, but there was no obvious change in fibretype composition. However, like $T b \times 15^{+/-}$and $T b \times 15^{-/-}$ animals, muscle fibre size in the $I g f 2$ knockout mice was markedly increased despite the decreased muscle mass (Fig. 5f). Although Igf2 has been thought to be expressed specifically in fast-twitch fibres at E14.5 (ref. 28) and distinct fast- and slow-twitch muscle fibres are found during embryonic development, we found that skeletal muscle of E14.5 embryos expresses fast myosin heavy 
a

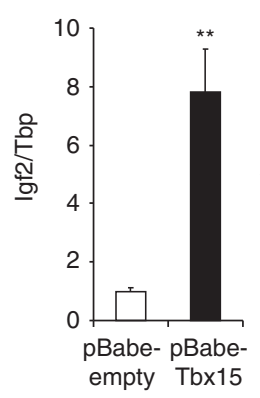

d

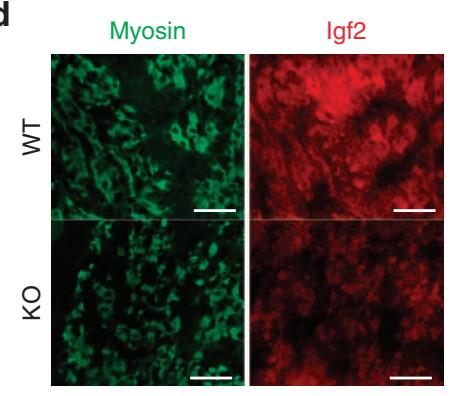

b
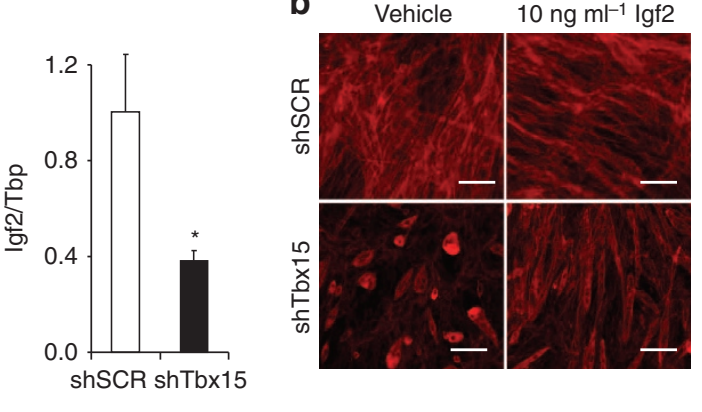

C

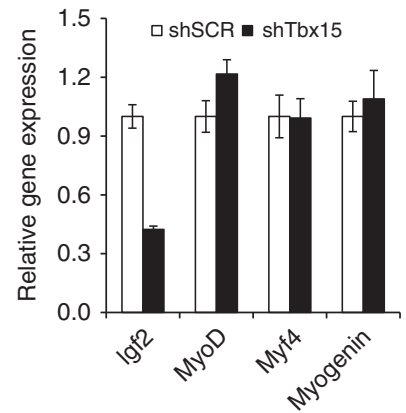

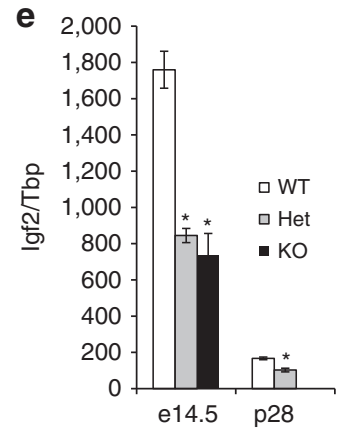
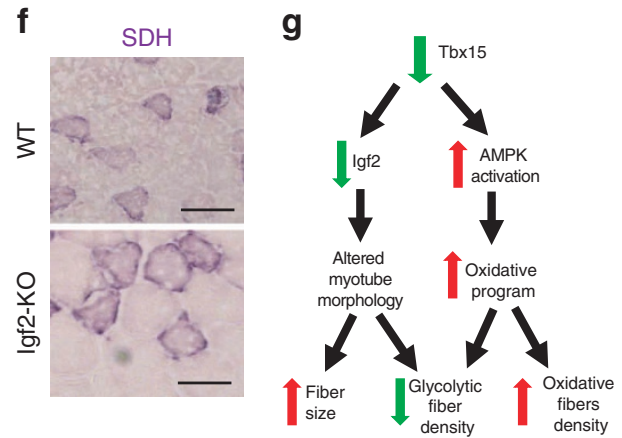

Figure 5 | Tbx15 regulates Igf2 and is critical for myotube formation. (a) Expression level of lgf2 mRNA assessed by qPCR in C2C12 myoblasts stably transfected with pBABE-Tbx15 and pBABE-Empty (control), and C2C12 myoblasts stably transfected with shTbx15 and shGFP (control). Data shown as the means \pm s.e.m.'s of three independently transfected samples ( ${ }^{\star} P<0.05$ for all panels by Student's $t$-test). (b) Phalloidin-Alexa-546 staining of shTbx15 and shGFP (control) myotubes after 4 days of differentiation either treated with vehicle $(0.1 \% \mathrm{BSA})$ or $10 \mathrm{ng} \mathrm{ml}^{-1}$ recombinant lgf2. Pictures were taken at $\times 10$ magnification. Scale bar, $50 \mu \mathrm{M}$. (c) Expression level of Igf2, MyoD, Myf5 and myogenin mRNA was assessed by qPCR in C2C12 myoblasts stably transfected with shTbx15 and shGFP (control) myotubes after 4 days of differentiation. Data are shown as mean \pm s.e.m. of three independently transfected samples. The experiment was repeated three times. (d) Immunofluorescence staining for total myosin isoforms (left) and lgf2 (right) from developing muscles in the limb buds of wild-type (WT) and Tbx15-/- E14.5 embryos. Pictures are taken at $\times 20$ magnification. Scale bar, $100 \mu$ M. (e) Expression level of Igf2 mRNA was compared by qPCR in dissected limb muscle from WT, Tbx15 ${ }^{+/-}$and Tbx15 $/-$E14.5 embryos and from tibialis anterior skeletal muscle from at WT and $\mathrm{Tb}_{\mathrm{N}} 15^{-/-}$male mice at p28. Values are means \pm s.e.m. of four to six animals per group. (f) Succinate dehydrogenase $(\mathrm{SDH})$ staining of tibialis anterior muscle from 8-week-old WT and lgf2 knockout $(n=3)$. Pictures were taken at $\times 20$. Scale bar, $50 \mu \mathrm{M}$. $(\mathbf{g})$ Model of Tbx15 action in skeletal muscle.

chain, irrespective of genotype (Supplementary Fig. 6c). However, by day $28, \mathrm{SDH}$ staining revealed clear differences in fibre composition between WT and Tbx $15^{+/-}$muscles (Supplementary Fig. 6d). Taken together, these data suggest that changes in Igf2 levels during embryogenesis do not lead to changes in fibre type, however, loss of Igf2 at this time may lead to alterations in myogenesis and fibre size.

To test whether the change in morphology and size exhibited by $\operatorname{sh}$ Tbx 15 myotubes was due to lack of Igf 2 expression, we treated shTbx15 and control myotubes with recombinant Igf2 $\left(10 \mathrm{ng} \mathrm{ml}^{-1}\right)$ in vitro throughout the 4 days of differentiation. Whereas the morphology of control myotubes was not affected by Igf2 treatment, Igf2 treatment partially rescued both the reduced myotube density, as well as the shorter, thicker morphology exhibited by the shTbx15 myotubes treated with vehicle only (Fig. 5b). Thus, Igf 2 appears to be one mediator of Tbx15 action in skeletal muscle with specific effects on regulation of myogenesis and fibre size.

Tbx15 regulates IGF-2 transcription via an indirect mechanism. Gene regulation and enhancer elements that regulate IGF-2 expression have been extensively studied. The distal enhancer region (CS9) and the proximal promoter region (P3) that are necessary and sufficient for muscle-specific expression of IGF-2 have been previously been defined ${ }^{30}$. Luciferase constructs driven by the $\mathrm{P} 3$ promoter element or a combination of the $\mathrm{P} 3$ promoter and CS9 enhancer region were transiently transfected into control and shTbx15 C2C12 myoblasts. Transcriptional activity from both the P3 promoter element or the P3 promoter and CS9 enhancer region was reduced by $\sim 27 \%(P<0.05)$ in shTbx15 cells compared with control cells in both cases (Supplementary Fig. 6e). To see whether Tbx15 was directly responsible for this effect, we co-transfected the luciferase constructs with different amounts of a Tbx15 expression plasmid into a heterologous cell line, 293FT cells, that do not express Tbx15. In this context, Tbx15 did not transactivate the IGF-2 promoter luciferase constructs (Supplementary Fig. 6f). Taken together, these data suggest that Tbx15 transcriptionally regulates IGF-2, but this effect is most likely indirect.

\section{Discussion}

The ability of muscle to differentiate into different fibre types plays an important role in muscle function and muscle and whole-body metabolism. In the present study, we demonstrate that the mesodermal transcription factor T-box15 is a critical factor controlling the fibre type determination and metabolism of muscle fibres. This is particularly true in the formation of glycolytic fast-twitch fibres. Several other factors have also been demonstrated to increase mass and function of glycolytic muscle fibres and have beneficial effects on glucose homeostasis. 
Reduction of myostatin signalling by either genetic or pharmacological treatment with soluble activin receptor type IIB leads to an increase in glycolytic muscle mass and improved glucose tolerance ${ }^{31,32}$. Similarly, constitutive activation of Akt in skeletal muscle increases glycolytic muscle mass, and results in loss of fat mass and metabolic improvement

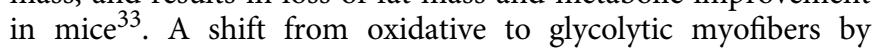
activation of Akt in skeletal muscle also occurs by overexpression of Baf60c and Deptor and this improves glucose metabolism even in the absence of muscle hypertrophy ${ }^{11}$. While all of the above manipulations increase glycolytic fibre density, knockout or knockdown of Tbx15 limits the development of glycolytic muscle fibres.

Tbx15 is highly and specifically expressed within glycolytic skeletal muscle fibres, and ablation of Tbx15 leads to marked decrease in number glycolytic fibres and a modest increase in the number of oxidative fibres. The reduction in the ratio of glycolytic to oxidative fibres leads to a muscle with a higher density of oxidative fibres as evidenced by both biochemical and immunofluorescence staining, as well as the slower contraction and relaxation rates, characteristic of oxidative fibres. The loss of glycolytic fibres in Tbx15-deficient mice results in a reduction of total muscle mass and total fibre number. Although these reductions do not lead to changes measurable changes in muscle performance either ex vivo or in vivo, at the whole-body level, the reduction in total muscle mass is associated with decreased spontaneous activity during both the light and dark phases of the diurnal cycle. This ultimately leads to decreased energy expenditure, increased lipid accumulation in adipose tissue and liver, and glucose intolerance. Since Tbx15 is most highly expressed in the skeletal muscle, and other tissues that can have effects on activity, such as the central nervous system, cardiovascular system, lungs and most endocrine organs do not express Tbx15, we believe the defects in skeletal muscle contribute to the reduced activity of the Tbx15deficient mice.

Although previous cell culture studies have postulated a role for Tbx15 in the development of brown adipose tissues ${ }^{34}$, we found no differences in brown fat formation, morphology or heat production in either the homozygous or heterozygous wholebody Tbx15-deficient mice, suggesting a minimal contribution of brown fat to the metabolic phenotypes we observe.

The effect of ablation of $T b \times 15$ to decrease glycolytic and increase oxidative fibre density occurs with no significant changes in several known regulators of muscle fibre type. Although genes with known higher expression in oxidative fibres, including PGC-1 $\alpha$ and RIP140, were tended to be increased in the quadriceps, EDL and soleus muscles on reduction of Tbx15, these results did not reach statistical significance. The increase in these of these genes may reflect the differences in fibre composition on reduction of Tbx15. On the other hand, reduction of $T b \times 15$ in skeletal muscle and cell lines does result in activation of AMPK, an enzyme known to play a role in muscle fibre determination, skeletal muscle metabolism and regulation of muscle metabolism in response to exercise ${ }^{35,36}$. Exactly how loss of Tbx15 activates AMPK signalling remains unknown, but our immunofluorescence and cell fractionation studies clearly demonstrate that a significant fraction of Tbx15 is present in the cytoplasm, in addition to the nucleus, of skeletal muscle cells. Extranuclear localization has been observed for other T-box proteins ${ }^{37,38}$. Although we were unable to co-precipitate Tbx15 and AMPK subunits (data not shown), it is possible that Tbx15 and AMPK interact directly or indirectly. Indeed, stable knockdown of Tbx15 in C2C12 cells recapitulates this effect on AMPK indicating the effect on AMPK occurs in a cell autonomous manner.
Furthermore, activation of the AMPK signalling axis directly represses mTor signalling. Thus, phosphorylation of mTor S2448 and its downstream phosphorylation target $\mathrm{p} 70^{\mathrm{S} 6 \mathrm{~K} 1} \mathrm{~T} 389$ were significantly reduced in Tbx15 $1 /-$ muscle in which AMPK activity is high. Although activation of the Akt-mTor signalling axis has been shown to positively regulate fibre size ${ }^{39}$, in the context of reduced Tbx15, fibre size and mTor signalling are not correlated. This suggests that other molecular regulators may be important for fibre size, or that the increase in fibre size might constitute a compensatory hypertrophy triggered by the loss in the number of myofibers.

As noted above, heterozygous and homozygous ablation of Tbx15 leads to dose-dependent decrease in glycolytic fibre number. This loss of glycolytic fibres far exceeds the increase in oxidative fibres leading to an overall decrease in fibre number. Thus, the loss of glycolytic fibres is not simply due to a transformation into oxidative fibres, indicating that Tbx15 is required for normal glycolytic myofiber formation.

At the transcriptional level, one target of Tbx15 is Igf2. Analysis of the Igf2 promoter suggests that it may be an indirect target of Tbx15. Consistent with a role as a regulator of myogenesis during embryonic development, the expression of Tbx15 and Igf 2 is much higher during embryogeneis than in adult skeletal muscle. Stable knockdown of $\mathrm{Tbx} 15$ in $\mathrm{C} 2 \mathrm{C} 12$ cells leads to the development of fewer myotubes, and these myotubes are both shorter and thicker. In Tbx15 homozygous and heterozygous knockout mice, muscle fibres also exhibit increased diameter. In vitro, this phenotype is partially rescued by exogenous Igf2 administration indicating that the change in myotube morphology and number is at least partially mediated by Igf2. Furthermore, Igf 2 null animals recapitulate part of the phenotype observed on ablation of Tbx15 with reduced muscle mass and increased muscle fibre size. However, unlike the ablation of Tbx 15, knockout of Igf2 has no effect on the ratio of oxidative to glycolytic muscle fibre. Together, these data indicate that Tbx15 regulates fibre size and number during embryogenesis at least in part via Igf2, but Tbx15 also has a separate role in establishing glycolytic versus oxidative fibre density during postnatal fibre-type formation.

In conclusion, Tbx15 plays a critical role in the formation, contractile properties and metabolism of skeletal muscle through determination of the glycolytic muscle fibre type. As summarized in Fig. 5h, our data indicate that ablation of Tbx15 results in activation of AMPK signalling and decreased in Igf2 expression. The increase in AMPK signalling activates oxidative capacity in a cell autonomous manner, whereas the loss of Igf2 negatively regulates myofiber formation. These two mechanisms contribute to a loss of muscle mass due to a specific loss of glycolytic fibres and an increase in oxidative fibres. This results in a shift of muscle metabolism and function, and ultimately results in a shift of substrates from muscle to fat and liver where they are stored as lipids, leading to increased adiposity and glucose intolerance. Thus, Tbx15 has an important role in the regulation of glycolytic muscle development, and when it fails, this can lead to the development of metabolic syndrome phenotypes, including obesity, hepatosteatosis and glucose intolerance.

\section{Methods}

Animals and diets. Tbx $15^{+/-}$mice on a mixed genetic background ${ }^{17}$ were bred to yield WT, Tbx $15^{+/-}$and $T b \times 15^{-/-}$mice. Mice were allowed ad libitum access to water and food containing $22 \%$ calories from fat, $23 \%$ from protein and $55 \%$ from carbohydrates (Mouse Diet 9F 5020; PharmaServ). Male Igf2 knockout mice $^{29}$ and littermate control WT mice on a mixed genetic background were analysed at 6-8 weeks of age. All mice were housed in a mouse facility with a $12-\mathrm{h}-$ light/-dark cycle in a temperature-controlled room. Animal care and study protocols were approved by the Animal Care Committee of Joslin Diabetes Center and were in accordance with the National Institutes of Health guidelines. 
Succinate dehydrogenase staining. Cross-sections of individual skeletal muscles were cut from the mid-belly region of the muscle at $8 \mu \mathrm{m}$ in a cryostat $\left(-20^{\circ} \mathrm{C}\right)$. After drying for $5 \mathrm{~min}$ at room temperature, the sections were incubated for $30 \mathrm{~min}$ at $37^{\circ} \mathrm{C}$ in a solution (pH 7.6) containing $6.5 \mathrm{mM}$ sodium phosphate monobasic, $43.5 \mathrm{mM}$ sodium phosphate biphasic, $0.6 \mathrm{mM}$ nitroblue tetrazolium (N6876; Sigma) and $50 \mathrm{mM}$ sodium succinate. The sections were then rinsed three times for $30 \mathrm{~s}$ each in physiological saline, for $5 \mathrm{~min}$ in $15 \%$ ethanol and embedded in CC/Mount (Sigma).

Tissue fractionation. Fractionation of skeletal muscle was performed using a combination of previously described techniques ${ }^{40,41}$. Briefly, quadriceps and tibialis anterior muscles were dissected, combined and minced in ice cold PBS with $10 \mathrm{mM}$ EDTA and $0.05 \%$ trypsin for $5 \mathrm{~min}$. Tissue piece were washed three times with PBS plus $10 \mathrm{mM}$ EDTA, then homogenized in M1 buffer $(0.25 \mathrm{M}$ sucrose, $1 \mathrm{mM}$ EDTA, $10 \mathrm{mM}$ Tris- $\mathrm{HCl}$ ( $\mathrm{pH}$ 7.4), with protease and phosphatase inhibitors (Sigma)) using a Potter-Elvehjem homogenizer. Homogenates were centrifuged at $1,000 \mathrm{~g}$ to remove nuclei and unbroken cells. Nuclei were purified away from unbroken myotubes by filtering through $20 \mu \mathrm{M}$ cell strainers. The supernatant was then spun at $16,000 \mathrm{~g}$ to pellet mitochondria and plasma membranes (P1) and supernatant (S1). P1 was then resuspended in $0.5 \mathrm{ml}$ of M1 buffer, loaded on $5-25 \%$ linear Ficoll gradient and centrifuged for $30 \mathrm{~min}$ at 24,000 r.p.m. (SW. 41 rotor). The upper band containing the plasma membrane was removed from the gradient, washed in three volumes of M1 buffer and recentrifuged at $16,000 \mathrm{~g}$ to obtain pure plasma membrane isolates. S1 was then spun in at 48,000 r.p.m. to separate pelleted microsomes and cytosolic proteins.

Metabolic analysis. For metabolic analysis, 5-month-old $\mathrm{Tb} \times 15^{+/-}$and controls were housed individually and evaluated for ambulatory activity using an OPTO-M3 sensor system (Comprehensive Laboratory Animal Monitoring System, CLAMS; Columbus Instruments), which counts beam breaks for $60 \mathrm{~s}$ for each mouse, five times per hour during two full light/dark cycles. Indirect calorimetry was measured on the same mice using an open-circuit Oxymax system (Columbus Instruments). After a 48-h acclimation period, exhaust air was sampled for $60 \mathrm{~s}$ every $12 \mathrm{~min}$ in each cage consecutively for $72 \mathrm{~h}$ in the fed state for the determination of $\mathrm{O}_{2}$ and $\mathrm{CO}_{2}$.

Fed glucose was measured between 0900 hours and 1100 hours in tail vein blood samples (Ascensia Elite). Insulin was measured using rat insulin enzyme-linked immunosorbent assay with mouse standards (Crystal Chem). Intraperitoneal glucose $\left(2 \mathrm{~g} \mathrm{~kg}^{-1}\right.$ weight) and insulin tolerance (1.25 units per $\mathrm{kg}$ ) tests were performed in unrestrained conscious 5-6-month-old male mice after a 16 - and 4 -h fast, respectively.

Measurement of fibre size and type. Tibealis anterior muscle from 8-week-old animals ( $n=4-8$ per group) was fixed in $10 \%$ formalin and paraffin embedded. Eight-micromitre sections were SDH stained. Five digital images $(\times 20)$ from non-overlapping fields were taken from each slide (total 20 fields per group), and fibre areas were calculated using Image J software.

Rectus femoris quadriceps muscle from 8-week-old animals ( $n=4-6$ per group) were SDH stained. Whole muscles were photographed by taking overlapping digital images $(\times 20)$ and combining the photos using Autostitch software. Fibres were counted using Image J software.

Gene expression. Analysis of gene expression was conducted using qPCR. Total RNA was extracted using an RNeasy minikit (QIAGEN), and $3 \mu \mathrm{g}$ was reverse transcribed in $100 \mu$ l using a High Capacity cDNA Reverse Transcription Kit (Applied Biosystems). Five microlitre of diluted complementary DNA from the reverse transcription reaction $(1 / 10)$ was amplified with specific primers $(300 \mathrm{nM}$ each) in a 10- $\mu$ PCR reaction with a SYBR green PCR master mix (Applied Biosystems). Analysis of gene expression was carried out in an ABI Prism 7900 sequence detector with an initial denaturation at $95^{\circ} \mathrm{C}$ for $10 \mathrm{~min}$, followed by 40 PCR cycles, each consisting of $95^{\circ} \mathrm{C}$ for $15 \mathrm{~s}$ and $60^{\circ} \mathrm{C}$ for $1 \mathrm{~min}$. SYBR green fluorescence emission was monitored after each cycle. For each gene, mRNA expression was calculated relative to TBP. Amplification of specific transcripts was confirmed by melting curve profiles at the end of each PCR. Primer sequences are listed in Supplementary Table 1.

Western blot. Proteins were extracted from cells in RIPA buffer with $0.1 \%$ SDS. Thirty microgram of protein was subjected to SDS-polyacrylamide gel electrophoresis and transferred to polyvinylidine fluoride membranes. Uncropped images of gels of key western blot experiments are shown in Supplementary Fig. 7. Primary antibodies listed in Supplementary Table 2.

Immunofluorescence. Immunofluorescence was performed on frozen sections. Specific signals were detected with Alexa Fluor 564-, Alexa Fluor 488- and Alexa Fluor 405-conjugated secondary antibodies (1:500). Alexa Fluor 546 phalloidin (Life technologies) was used according to manufacturer's instructions. Primary antibodies are listed in Supplementary Table 2.
Isometric contraction measurements. The EDL was removed by dissection and kept in oxygenated Krebs-Henseleit solution (in mM): $120 \mathrm{NaCl}, 3.3 \mathrm{KCl}, 1.2$ $\mathrm{MgSO}_{4}, 1.2 \mathrm{KH}_{2} \mathrm{PO}_{4}, 1.3 \mathrm{CaCl}_{2}, 25 \mathrm{NaHCO}_{3}$, aerated with $5 \% \mathrm{CO}_{2} / 95 \% \mathrm{O}_{2}$. A fibre bundle of EDL was prepared in a Petri dish with spring scissors under a Wild M8 microscope (Leica). To measure isometric contractions, the fibre bundle was transferred into a chamber that was perfused with oxygenated $25 \mathrm{mM} \mathrm{HCO}_{3}^{-} / 5 \%$ $\mathrm{CO}_{2}$ buffered Krebs-Henseleit solution ${ }^{42}$. One end of the fibre bundle was fixed; the other was connected to a force transducer (SensoNor, Friedberg, Germany). The length of the fibre bundle was adjusted to give maximal isometric twitch tension. The fibres were directly stimulated by platinum wires at $25^{\circ} \mathrm{C}$ (stimulator S 48, Grass Instrument Division, W. Warwick, RI, USA). Single twitches were triggered by pulses of 1-ms duration and supramaximal voltage and tetani by pulses of 1-ms duration at $100 \mathrm{~Hz}$ for $400 \mathrm{~ms}$.

Recordings of single twitches were analysed for peak force, TTP and 50 and 75\% relaxation times (t50 and t75\%), respectively. Tetani were analysed for maximum tetanic force, $\mathrm{t} 50$ and $\mathrm{t} 75 \%$. The TTP is defined as the time interval between the time at which the trace deviates from baseline and the time at which peak force is achieved. $\mathrm{t} 50$ and $\mathrm{t} 75 \%$ are defined as the time interval between the peak value and the time at which the signal has decayed to 50 and $75 \%$ of peak force.

Ex vivo contraction. Muscle force production was determined as previously described ${ }^{43-46}$ with some modifications. Mice were anaesthetized $\left(90 \mathrm{mg} \mathrm{kg}^{-1}\right.$ pentobarbital intraperitoneal), killed by cervical dislocation and EDL muscles rapidly excised. Muscle length was measured with a micrometre, and muscles attached to a tissue support with stimulating electrodes (Harvard Apparatus, Holliston, MA, USA). Muscles were bathed in Krebs-Ringer Bicarbonate buffer containing (in mM): $117 \mathrm{NaCl}, 4.7 \mathrm{KCl}, 2.5 \mathrm{CaCl}_{2} \bullet 2 \mathrm{H}_{2} \mathrm{O}, 1.2 \mathrm{KH}_{2} \mathrm{PO}_{4}, 1.2$ $\mathrm{MgSO}_{4} \bullet 7 \mathrm{H}_{2} \mathrm{O}, 24.6 \mathrm{NaHCO}_{3}, 5.6$ glucose at $30^{\circ} \mathrm{C}, \mathrm{pH}$ 7.4, and continuously gassed with $95 \% \mathrm{O}_{2} / 5 \% \mathrm{CO}_{2}$. Optimal muscle length $\left(L_{\mathrm{O}}\right)$ was determined for each muscle by increasing the resting tension to $2.40 \mathrm{~g}$ and decreasing resting tension by $0.4 \mathrm{~g}$ increments and applying a single electrical pulse generated by a Grass stimulator (Harvard Apparatus, Holliston, MA, USA; parameters: pulse rate $=1$ pulse per second; duration $=1 \mathrm{~ms}$; volts $=100 \mathrm{~V})$. The tension $\left(L_{\mathrm{O}}\right)$ at which peak force was achieved was the tension applied to perform to the following contraction protocols. Force production was monitored using isometric force transducers (Kent Scientific, Litchfield, CT, USA), the converted digital signal was captured by a data acquisition system (iWorx114, CB Sciences, Dover, NH, USA), and assessed with analysis software (Labscribe, CB Sciences). Specific force was calculated by normalizing force measurements to total muscle CSA. Total CSA was determined by dividing muscle weight by the product of the muscle length and the average density of mammalian skeletal muscle $\left(1.06 \mathrm{mg} \mathrm{mm}^{-3}\right)$. Maximal twitch force was assessed by averaging four muscle twitches, maximally stimulated using the following electrical pulse parameters: (pulse rate $=1$ pulse per second; duration $=1 \mathrm{~ms}$; volts $=100 \mathrm{~V}$ ). Maximal tetanic force was assessed by averaging four tetanic contractions, maximally stimulated using the following electrical pulse parameters: (pulse rate $=130$ pulse per second; duration $=1 \mathrm{~ms}$; volts $=100 \mathrm{~V}$ ). Muscle fatigue rate was assessed by rate of decay of maximal twitch force during 40 repeated stimulations.

Test of muscle performance. Six-week-old $\mathrm{Tbx} 15^{+/-}$and male littermate control mice were randomly assigned to housing in individual cages with or without running wheels (Nalgene, Rochester, NY, USA) for a total of 3 weeks. Completed wheel revolutions and time spent running were monitored daily. On day 21, all mice were removed from their cages being killed by cervical dislocation.

Eight-week-old Tbx15 $5^{+/-}$and male littermate control mice were familiarized with the treadmill (Quinton model 42 ) by running $5-10$ min 2 days before the onset of experimentation. Animals were then subjected to an exhaustive 'ramp' protocol, as previously described ${ }^{47}$. Briefly, WT and Tbx $15^{+/-}$male mice at 8 week of age were subjected to a graded ramp treadmill running protocol. The treadmill speed began at 0.2 miles per hour and increased 0.2 miles per hour every 3 min until the speed reached 0.8 miles per hour. The incline was increased by $2.5 \%$ every $3 \mathrm{~min}$, to a maximum of $20 \%$. The speed and incline were then kept constant (0.8 mile per hour and $20 \%)$ until the mice reached exhaustion. Following acclimation, muscle strength of 8-week-old Tbx15 ${ }^{+/-}$and control mice was measured using an automated Grip Strength Meter (Columbus Instruments).

Reporter assays. For regulation of IGF- 2 constructs: shTbx 15 and control C2C12 cells or $293 \mathrm{FT}$ cells at $70 \%$ confluence in DMEM with $10 \%$ fetal bovine serum grown to were co-transfected with $1 \mu \mathrm{g}$ of a previously described of IGF-2 promoter constructs ${ }^{30}$, pBABE-Tbx15 or BABE-Empty and pRenilla-TK (Promega), using Superfect transfection reagent (Quiagen). All transfections were harvested $24 \mathrm{~h}$ later and luciferase activity was measured using a Dual Renilla Luciferase II Assay Kit, and normalized to Renilla luciferase measurements (Promega).

Retroviral and lentiviral infection. Short hairpin RNA knockdown of Tbx15 was achieved in mycoplasma-free (as tested with Plasmotest (InvivoGen)) C2C12 cells (ATCC) by lentiviral infection. Plates $(10 \mathrm{~cm})$ of $70 \%$ confluent $293 \mathrm{FT}$ cells were transiently transfected with $1 \mu \mathrm{g}$ of lentiviral shTbx15 in pLKO.1 (Catalog 
\#:TRCN0000084362) and the viral packaging vectors SV-E-MLV-env and SV-EMLV using Superfect (Qiagen) according to the manufacturer's instructions. Fortyeight hour after transfection, virus-containing medium was collected and passed through a $0.45-\mu \mathrm{m}$-syringe filter. Filter-sterilized Polybrene (hexadimethrine bromide, $8 \mu \mathrm{g} \mathrm{ml}^{-1}$ ) was added to the virus-loaded medium, and the medium was applied to proliferating cells. Forty-eight hour after infection, cells were treated with trypsin and replated in a medium supplemented with puromycin (Invitrogen) as a selection antibiotic.

Tbx15 was stably overexpressed in C3H10T1/2 cells by retroviral infection. Phoenix cells were grown to $70 \%$ confluency in $10-\mathrm{cm}$ plates and were transiently transfected with $1 \mu \mathrm{g}$ of retroviral expression vectors pBABE-Empty-puro or pBABE-Tbx15-puro using Superfect (Qiagen) according to the manufacturer's instructions. At $48 \mathrm{~h}$ after transfection, virus-containing medium was collected and passed through a $0.45-\mu \mathrm{m}$ pore-size syringe filter. Filter-sterilized Polybrene ( $8 \mathrm{\mu g} \mathrm{ml}^{-1}$ hexadimethrine bromide) was added to the virus-loaded medium, and the medium was then applied to proliferating ( $20 \%$ confluent) cells. At $48 \mathrm{~h}$ after infection, cells were treated with trypsin and replated in a medium supplemented with zeocin (Invitrogen) as a selection antibiotic.

Cells were grown in DMEM containing high glucose $\left(4,500 \mathrm{mgl}^{-1}\right)$ with $10 \%$ fetal bovine serum (Gemini). Differentiation was induced by treating cells with $2 \%$ heat-inactivated horse serum (Sigma) in DMEM containing high glucose $\left(4,500 \mathrm{mgl}^{-1}\right)$ for 4 days.

Microarray analysis of gene expression. RNA was extracted and biotin-labelled complementary RNA (cRNA) was prepared from three independent transfections of the four stable C2C12 myoblast cell lines described above: $s h T b x 15$, shGFP, pBABE-Empty-puro and pBABE-Tbx15-puro. Complementary RNA was hybridized to Affymetrix M430 2.0 arrays, and microarray analysis was performed on globally scaled data (MAS 5.0). Gene set enrichment analysis and ingenuity pathway analysis were used to determine significantly regulated pathways and gene networks.

Oil Red $\mathrm{O}$ staining. Liver samples from five 5-month-old male $\mathrm{Tb} \times 15^{+/-}$and littermate male control mice were embedded in OCT and sectioned $9-10-\mu \mathrm{m}$ thick. Oil Red O stock solution ( $0.5 \mathrm{~g}$ of Oil Red O (Sigma) in $100 \mathrm{ml}$ of isopropanol) was diluted with water $(60: 40(\mathrm{vol} / \mathrm{vol}))$, followed by filtration. After staining, samples were washed several times in water. Liver sections were lightly counterstained with haematoxylin. Pictures are taken at $\times 20$.

XF24 oxygen consumption assay and oxygen consumption rate. Oxygen consumption was measured using the XF24 Extracellular Flux Analyser from Seahorse Bioscience. For this, $2 \mathrm{~h}$ before the analysis, control, shTbx15 and Tbx15 overexpressing C2C12 myoblasts on 24-well XF24 V28 cell culture microplate (Seahorse Bioscience) were pretreated compound C. One hour before the experiment, cells were washed and incubated in $630 \mu \mathrm{l}$ of non-buffered (without sodium carbonate) DMEM $\left(4.5 \mathrm{gl}^{-1}\right.$ glucose $) \mathrm{pH} 7.4$ at $37^{\circ} \mathrm{C}$ in a non- $\mathrm{CO}_{2}$ incubator. Five replicates per cell type were included in the experiment, and four wells evenly distributed within the plate were used for correction of temperature variations. During the time course of the experiment, oxygen concentration was measured over time periods of $2 \mathrm{~min}$ at 6 -min intervals, consisting of a $2 \mathrm{~min}$ of mixing period and a 4 min waiting period. OCR over the 2 min measurement period was calculated using the Fixed Delta technique for determining the slope.

Study design and statistics. Studies were conducted in a non-blinded fashion. For all studies, samples were not randomized, and sample size (range from $n=3$ to $n=14)$ are explicitly stated in the figure legends. Normal distribution was assessed by the Jarque-Bera test $(P>0.05)$. All differences were analysed by analysis of variance, or Student's $t$-test if normally distributed. The Mann-Whitney $U$-test was used for data that was not normally distributed. Results were considered significant if $P<0.05$.

\section{References}

1. He, J., Watkins, S. \& Kelley, D. E. Skeletal muscle lipid content and oxidative enzyme activity in relation to muscle fiber type in type 2 diabetes and obesity. Diabetes 50, 817 (2001).

2. Hickey, M. S. et al. Skeletal muscle fiber composition is related to adiposity and in vitro glucose transport rate in humans. Am. J. Physiol. 268, E453-E457 (1995).

3. Nyholm, B. et al. Evidence of an increased number of type IIb muscle fibers in insulin-resistant first-degree relatives of patients with NIDDM. Diabetes 46, $1822(1997)$

4. Tanner, C. J. et al. Muscle fiber type is associated with obesity and weight loss. Am. J. Physiol. Endocrinol. Metab. 282, E1191-E1196 (2002).

5. Marin, P., Andersson, B., Krotkiewski, M. \& Bjorntorp, P. Muscle fiber composition and capillary density in women and men with NIDDM. Diabetes Care 17, 382 (1994)
6. Chin, E. R. et al. A calcineurin-dependent transcriptional pathway controls skeletal muscle fiber type. Genes Dev. 12, 2499 (1998).

7. DiMario, J. X. Protein kinase C signaling controls skeletal muscle fiber types. Exp. Cell Res. 263, 23 (2001).

8. Fryer, L. G. et al. Characterization of the role of the AMP-activated protein kinase in the stimulation of glucose transport in skeletal muscle cells. Biochem. J. 363, 167 (2002).

9. Lin, J. et al. Transcriptional co-activator PGC-1 alpha drives the formation of slow-twitch muscle fibres. Nature 418, 797 (2002).

10. Rockl, K. S. et al. Skeletal muscle adaptation to exercise training: AMP-activated protein kinase mediates muscle fiber type shift. Diabetes 56, 2062 (2007)

11. Meng, Z. X. et al. Baf60c drives glycolytic metabolism in the muscle and improves systemic glucose homeostasis through Deptor-mediated Akt activation. Nat. Med. 19, 640 (2013).

12. Herrmann, B. G., Labeit, S., Poustka, A., King, T. R. \& Lehrach, H. Cloning of the $\mathrm{T}$ gene required in mesoderm formation in the mouse. Nature 343, 617 (1990).

13. Kispert, A. \& Herrmann, B. G. The Brachyury gene encodes a novel DNA binding protein. $Е M B O$ J. 12, 3211 (1993).

14. Takashima, Y. \& Suzuki, A. Regulation of organogenesis and stem cell properties by T-box transcription factors. Cell. Mol. Life Sci. 70, 3929 (2013).

15. Candille, S. I. et al. Dorsoventral patterning of the mouse coat by Tbx15. PLoS Biol. 2, E3 (2004).

16. Lausch, E. et al. TBX15 mutations cause craniofacial dysmorphism, hypoplasia of scapula and pelvis, and short stature in Cousin syndrome. Am. J. Hum. Genet. 83, 649 (2008).

17. Singh, M. K. et al. The T-box transcription factor Tbx15 is required for skeletal development. Mech. Dev. 122, 131 (2005).

18. Farin, H. F. et al. Transcriptional repression by the T-box proteins Tbx18 and Tbx15 depends on Groucho corepressors. J. Biol. Chem. 282, 25748 (2007).

19. Gesta, S. et al. Evidence for a role of developmental genes in the origin of obesity and body fat distribution. Proc. Natl Acad. Sci. USA 103, 6676 (2006)

20. Heid, I. M. et al. Meta-analysis identifies 13 new loci associated with waist-hip ratio and reveals sexual dimorphism in the genetic basis of fat distribution. Nat. Genet. 42, 949 (2010).

21. Gesta, S. et al. Mesodermal developmental gene Tbx15 impairs adipocyte differentiation and mitochondrial respiration. Proc. Natl Acad. Sci. USA 108, 2771 (2011).

22. Lin, J., Handschin, C. \& Spiegelman, B. M. Metabolic control through the PGC-1 family of transcription coactivators. Cell Metab. 1, 361 (2005).

23. LeBrasseur, N. K., Walsh, K. \& Arany, Z. Metabolic benefits of resistance training and fast glycolytic skeletal muscle. Am. J. Physiol. Endocrinol. Metab. 300, E3 (2011).

24. Witczak, C. A., Sharoff, C. G. \& Goodyear, L. J. AMP-activated protein kinase in skeletal muscle: from structure and localization to its role as a master regulator of cellular metabolism. Cell. Mol. Life Sci. 65, 3737 (2008).

25. Ruderman, N. B., Carling, D., Prentki, M. \& Cacicedo, J. M. AMPK, insulin resistance, and the metabolic syndrome. J. Clin. Invest. 123, 2764 (2013).

26. Sarbassov, D. D., Ali, S. M. \& Sabatini, D. M. Growing roles for the mTOR pathway. Curr. Opin. Cell Biol. 17, 596 (2005).

27. Florini, J. R. et al. Spontaneous differentiation of skeletal myoblasts is dependent upon autocrine secretion of insulin-like growth factor-II. J. Biol. Chem. 266, 15917 (1991).

28. Merrick, D., Ting, T., Stadler, L. K. \& Smith, J. A role for Insulin-like growth factor 2 in specification of the fast skeletal muscle fibre. BMC Dev. Biol. 7, 65 (2007).

29. DeChiara, T. M., Efstratiadis, A. \& Robertson, E. J. A growth-deficiency phenotype in heterozygous mice carrying an insulin-like growth factor II gene disrupted by targeting. Nature 345, 78 (1990).

30. Alzhanov, D. T., McInerney, S. F. \& Rotwein, P. Long range interactions regulate Igf2 gene transcription during skeletal muscle differentiation. J. Biol. Chem. 285, 38969 (2010).

31. Akpan, I. et al. The effects of a soluble activin type IIB receptor on obesity and insulin sensitivity. Int. J. Obes. (Lond) 33, 1265 (2009).

32. Guo, T. et al. Myostatin inhibition in muscle, but not adipose tissue, decreases fat mass and improves insulin sensitivity. PLoS ONE 4, e4937 (2009).

33. Izumiya, Y. et al. Fast/glycolytic muscle fiber growth reduces fat mass and improves metabolic parameters in obese mice. Cell Metab. 7, 159 (2008).

34. Gburcik, V., Cawthorn, W. P., Nedergaard, J., Timmons, J. A. \& Cannon, B. An essential role for Tbx15 in the differentiation of brown and "brite" but not white adipocytes. Am. J. Physiol. Endocrinol. Metab. 303, E1053-E1060 (2012).

35. Lee-Young, R. S. et al. Skeletal muscle AMP-activated protein kinase is essential for the metabolic response to exercise in vivo. J. Biol. Chem. 284, 23925 (2009)

36. Rockl, K. S., Witczak, C. A. \& Goodyear, L. J. Signaling mechanisms in skeletal muscle: acute responses and chronic adaptations to exercise. IUBMB Life $\mathbf{6 0}$, 145 (2008) 
37. Bimber, B., Dettman, R. W. \& Simon, H. G. Differential regulation of Tbx 5 protein expression and sub-cellular localization during heart development. Dev. Biol. 302, 230 (2007).

38. Krcmery, J., Camarata, T., Kulisz, A. \& Simon, H. G. Nucleocytoplasmic functions of the PDZ-LIM protein family: new insights into organ development. Bioessays 32, 100 (2010).

39. Pallafacchina, G., Calabria, E., Serrano, A. L., Kalhovde, J. M. \& Schiaffino, S. A protein kinase B-dependent and rapamycin-sensitive pathway controls skeletal muscle growth but not fiber type specification. Proc. Natl Acad. Sci. USA 99, 9213 (2002).

40. Frezza, C., Cipolat, S. \& Scorrano, L. Measuring mitochondrial shape changes and their consequences on mitochondrial involvement during apoptosis. Methods Mol. Biol. 372, 405 (2007).

41. McKeel, D. W. \& Jarett, L. Preparation and characterization of a plasma membrane fraction from isolated fat cells. J. Cell Biol. 44, 417 (1970).

42. Wetzel, P., Kleinke, T., Papadopoulos, S. \& Gros, G. Inhibition of muscle carbonic anhydrase slows the $\mathrm{Ca}(2+)$ transient in rat skeletal muscle fibers. Am. J. Physiol. Cell Physiol. 283, C1242-C1253 (2002).

43. Cerletti, M. et al. Highly efficient, functional engraftment of skeletal muscle stem cells in dystrophic muscles. Cell 134, 37 (2008).

44. Hayashi, T., Hirshman, M. F., Kurth, E. J., Winder, W. W. \& Goodyear, L. J. Evidence for 5' AMP-activated protein kinase mediation of the effect of muscle contraction on glucose transport. Diabetes 47, 1369 (1998).

45. Rowe, G. C. et al. Disconnecting mitochondrial content from respiratory chain capacity in PGC-1-deficient skeletal muscle. Cell Rep. 3, 1449 (2013)

46. Sinha, M. et al. Restoring systemic GDF11 levels reverses age-related dysfunction in mouse skeletal muscle. Science 344, 649 (2014).

47. Fujii, N. et al. Role of AMP-activated protein kinase in exercise capacity, whole body glucose homeostasis, and glucose transport in skeletal muscle -insight from analysis of a transgenic mouse model. Diabetes Res. Clin. Pract. 77(Suppl 1): S92-S98 (2007).

\section{Acknowledgements}

This work was supported by NIH grant R01 DK 082655 (C.R.K.), the Joslin DRC P30 DK 036836, the Joslin training grant T32DK007260, an American Diabetes Association mentor-based award (C.R.K.), the Mary K. Iacocca Professorship (C.R.K.), a grant from the German Research Council DFG KI728/3 (A.K.), iMed, the Helmholtz Initiative on
Personalized Medicine (S.U.), the German Center for Diabetes Research, DZD (S.U.), and NIH grant RO1 AR042238 (L.J.G.). We thank Mary Frances Lopez (Boston Children's Hospital) for the Igf2 knockout mice and Dr Peter Rotwein (Oregon Health and Science University) for the Igf2 promoter constructs. We are grateful to Christie Penniman for animal care; and A. Clermont, M. Poillucci (DRC Physiology Core), H. Li (DRC Specialized Assay Core) and J. Schroeder (DRC Genomics Core) for technical assistance.

\section{Author contributions}

K.Y.L. designed and performed the experiments, analysed the data and wrote the paper; M.K.S., S.U, P.W, M.F.H. and L.J.G. designed and performed the experiments; A.K. and C.R.K. designed the experiments, analysed the data and wrote the paper. All authors discussed the results and implications and commented on the manuscript at all stages.

\section{Additional information}

Accession code: Microarray data have been deposited into the NCBI GEO data repository under accession code GSE70489.

Supplementary Information accompanies this paper at http://www.nature.com/ naturecommunications

Competing financial interests: The authors declare no competing financial interests.

Reprints and permission information is available online at http://npg.nature.com/ reprintsandpermissions/

How to cite this article: Lee, K. Y. et al. Tbx15 controls skeletal muscle fibre-type determination and muscle metabolism. Nat. Commun. 6:8054 doi: 10.1038/ncomms9054 (2015).

(c) (i) This work is licensed under a Creative Commons Attribution 4.0 International License. The images or other third party material in this article are included in the article's Creative Commons license, unless indicated otherwise in the credit line; if the material is not included under the Creative Commons license, users will need to obtain permission from the license holder to reproduce the material. To view a copy of this license, visit http://creativecommons.org/licenses/by/4.0/ 